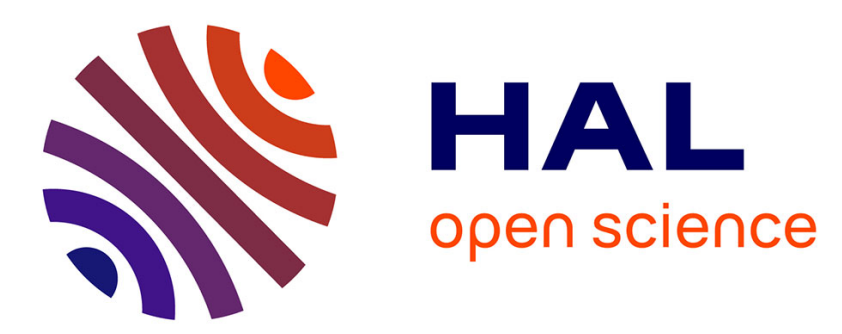

\title{
Fracture roughness and thermal exchange: A case study at Soultz-sous-Forêts
}

\author{
Amélie Neuville, Renaud Toussaint, Jean Schmittbuhl
}

\section{To cite this version:}

Amélie Neuville, Renaud Toussaint, Jean Schmittbuhl. Fracture roughness and thermal exchange: A case study at Soultz-sous-Forêts. Comptes Rendus Géoscience, 2010, 342 (7-8), pp.616-625. 10.1016/j.crte.2009.03.006 . hal-02377772

\section{HAL Id: hal-02377772 \\ https://hal.science/hal-02377772}

Submitted on 24 Nov 2019

HAL is a multi-disciplinary open access archive for the deposit and dissemination of scientific research documents, whether they are published or not. The documents may come from teaching and research institutions in France or abroad, or from public or private research centers.
L'archive ouverte pluridisciplinaire HAL, est destinée au dépôt et à la diffusion de documents scientifiques de niveau recherche, publiés ou non, émanant des établissements d'enseignement et de recherche français ou étrangers, des laboratoires publics ou privés. 


\section{FRACTURE ROUGHNESS AND THERMAL EXCHANGE: A CASE STUDY AT SOULTZ-SOUS-FORÊTS RUGOSITE DE FRACTURE ET ECHANGE THERMIQUE: ETUDE DE CAS A SOULTZ-SOUS-FORETS}

Amélie Neuville, Renaud Toussaint, Jean Schmittbuhl

*Institut de Physique du Globe de Strasbourg, UMR CNRS ULP 7516

EOST, Université Louis Pasteur, 5 Rue René Descartes, 67084 Strasbourg, France

e-mail: amelie.neuville@eost.u-strasbg.fr ;Tel: +33 (0) 3.90.24.00.51

\section{ABSTRACT}

Heat exchange during laminar flow in an open fracture is studied numerically on the basis of the Stokes equation in the limit of hydro-thermal lubrication. We examine the influence of fracture roughness on hydraulic permeability and heat flux through the fracture sides when a cold fluid is injected into a homogeneous hot host rock. Spatial temperature fluctuations inside the fluid are studied assuming the temperature of the rock to be constant and the fracture aperture to be self-affine. An application to the case study at the deep geothermal reservoir of Soultz-sous-Forêts, France, is presented. Finally, a thermal model based on sparse spatial information of the geometrical aperture is successfully proposed to reproduce the response of the fracture.
\end{abstract}

Keywords: fracture, roughness, lubrication, heat exchange, Soultz-sous-Forêts

\section{RESUME}

L'échange de chaleur en régime laminaire est étudié numériquement dans une fracture ouverte sur la base de l'équation de Stokes, dans la limite de l'hypothèse de lubrification hydro-thermique. Nous observons l'influence de la rugosité sur la perméabilité hydraulique ainsi que sur le flux de chaleur à travers les parois de la fracture quand un fluide froid est injecté dans une roche mère ayant une température chaude homogène. Les fluctuations de la température du fluide sont étudiées en supposant que la température de la roche est constante et la fracture auto-affine. Une application au cas d'étude du réservoir de géothermie profonde à Soultz-sous-Forêts, France, est présentée. Finalement, nous proposons un modèle thermique basé sur la connaissance spatiale réduite de l'ouverture géométrique, qui reproduit bien la réponse de la fracture.

Mots-clefs: fracture, rugosité, lubrification, échange de chaleur, Soultz-sous-Forêts

\section{INTRODUCTION}

Modeling of the fluid transport in low permeable crustal rocks is of central importance for many applications [19]. Among them is the monitoring of the geothermal circulation in the project of Soultz-sous-Forêts, France, [1] where the heat exchange especially occurs through open fractures in granite [10].

Numerous hydro-thermal models have already been proposed. For simple geometries some analytical solutions are known: e.g. the cases of parallel plates (e.g. [35]) or flat cylinders [11]. More complex models exist as well like the models of three dimensional (3D) networks of fractures reproducing geological observations and possibly completed with stochastical distributions of fractures (e.g. in Soultzsous-Forêts, France, [9; 24] or in Rosemanowes, UK [13]). Nevertheless, the geometry of each fracture is generally simple. Kolditz and Clauser (1998) [13] have however suspected that differences between heat models and field observations could be due to channeling induced by the fracture roughness or the fracture network. Channeling of the fluid flow owing to fracture roughness has indeed already been experimentally observed (e.g [16;21;31]).

Here, we limit our study to the fracture scale. The specificity of our hydro-thermal model is to take into account the different scale fluctuations of the fracture morphology. We aim at bringing out the main parameters which control the hydraulic and thermal behavior of a complex rough fracture. The perspective is to propose a small set of effective parameters that could be introduced within simplified elements for an upscaled network model.

We first describe our geometrical model of the fracture aperture thanks to self-affine apertures. Then using lubrication approximations, we obtain the bidimensional (2D) pressure and thermal equations when a cold fluid is injected through the fracture in a stationary regime. The temperature within the surrounding rock is supposed to be hot and constant in time and space. The fluid density is also supposed to be constant. We locally assume that the equation for heat flux is identical to the one dimensional (1D) basic one for parallel plates, but with an adjusted characteristic thermal length: we define a thermal aperture which could significantly differ from the local geometrical aperture.

We apply our numerical model to the case study at Soultzsous-Forêts and we show for this case an example of computed hydraulic and thermal behavior. Finally we aim at bringing out what is the minimal geometrical information needed to get the dominant behavior of the hydraulic and thermal fields. This last approach is based on spatial Fourier filtering of the geometrical aperture field.

\section{MODELING}

Roughness of the fracture aperture

We consider that the mean fracture plane is described by the $(\hat{x}, \hat{z})$ coordinates and the perpendicular direction is $\hat{y}$ (Figure 1 ) - where the hat notation refers to unit vectors along the $(x, y, z)$ axis. It has been shown that a possible geometrical model of natural rough fractures consists in selfaffine surfaces. A surface described by a function $y=f(x, z)$ is self-affine if it is statistically invariant under the scaling transformation $x \rightarrow \lambda x, z \rightarrow \lambda z$ and $y \rightarrow \lambda^{\zeta} y$, where $\zeta$ is called the roughness exponent or Hurst exponent. Such surfaces are therefore statistically invariant upon an isotropic scaling within their mean plane while along the perpendicular direction, the scaling is anisotropic (e.g. [7; 22; 8; 29; 30]. Most fracture surfaces in heterogeneous material exhibit a 
Hurst exponent equal to $\zeta=0.8$ [5;29; 30; 27]. Sandstone fractures however show $\zeta=0.5[4 ; 15]$.

It is important to note that a self-affine surface having a roughness exponent smaller than one is asymptotically flat at large scales [25]. Accordingly, the self-affine topography can be seen as a perturbation of a flat interface. When the lubrication approximation [20] holds, in particular with smooth enough self-affine perturbations or highly viscous fluid, only the local aperture controls the flow and not the slope of the fracture. Under this assumption, the only required geometrical input is the aperture field (also called the geometrical aperture); there is especially no need to know the geometry of each facing fracture surfaces. The aperture between two uncorrelated self-affine fracture surfaces having the same roughness exponent is as well self-affine [18]. Thus we generate the numerical apertures by using self-affine functions.

Several independent self-affine aperture morphologies can be generated with the same roughness exponent chosen equal to $\zeta=0.8$. They exhibit various morphology patterns according to the chosen seed of the random generator [15]. The mean geometrical aperture $A$ and the root-mean square deviation $\sigma$ (RMS) of an aperture $a(x, z)$ are defined as $A=\left(\iint a d x d z\right) /\left(l_{x} \cdot l_{z}\right)$ and $\sigma=\left(\iint a^{2} d x d z\right) /\left(l_{x} \cdot l_{z}\right)$ with $l_{x}$ the length and $l_{z}$ the height of the fracture. To keep the boundary geometry of the domain as simple as possible, we do not allow any contact area (i.e. no local aperture equal to zero). This is obtained by considering a large enough aperture average to get strictly positive aperture fields.

It has to be noted that our hydro-thermal model can be applied to other geometrical models (i.e. different from a self-affine model) which might be more relevant depending on the geological context.

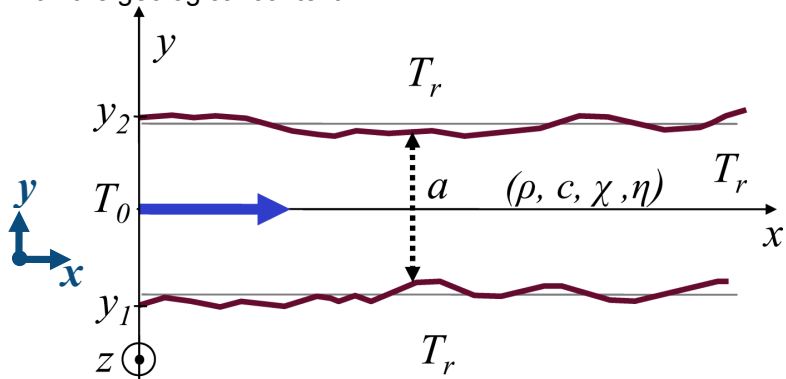

Figure 1: Schematic fracture with variable aperture a $(x, z)$; $\rho, c, \chi, \eta$ are respectively the following fluid properties: density, heat capacity, thermal diffusivity and dynamic viscosity. Schéma de fracture d'ouverture variable a $(x, z)$; $\rho, c, \chi, \eta$ sont les propriétés respectives suivantes du fluide: densité, capacité thermique, diffusivité thermique et viscosité dynamique.

\section{Physics of hydraulic flow}

The hydraulic flow is obtained under the same hypotheses and solved in the same way as in Méheust \& Schmittbuhl, (2001) [17]. We use finite differences, and the system of linear equations is inverted using an iterative biconjugate gradient method [23].

We impose a pressure drop across the system and study the steady state flow of a Newtonian fluid at low Reynolds number, so that the viscous term dominates the inertial one in the Navier-Stokes equation [33; 3]: $\vec{\nabla} P=\eta \Delta \vec{u}^{3 D}$, where $\eta$ is the dynamic viscosity, $u^{3 D}$ the velocity of the fluid and $P$ is the pressure deviation from the hydrostatic profile (or the hydraulic head equal to the pressure corrected by the gravity effect). To be in the framework of the lubrication approximation [20], we consider fractures with constant enough apertures together with a small Reynolds number. In doing so the velocity vector of the fluid flow has negligible components normal to the mean fracture plane. We consider that the macroscopic pressure gradient is imposed along $\hat{x}$; $\hat{z}$ is therefore perpendicular to the mean flow direction. Accordingly the fluid velocity follows a parabolic law (e.g. [12]) (Figure 2):

$$
\vec{u}^{3 D}(x, y, z)=\frac{\vec{\nabla}_{2} P}{2 \eta}\left(y-y_{1}\right)\left(y-y_{2}\right) \text { [Eq. 1], }
$$

where $y_{1}$ and $y_{2}$ are the local fracture sides coordinates and $\vec{\nabla}_{2}$ is the gradient operator in the fracture plane. The hydraulic flow through the fracture aperture follows a cubic law:

$$
\vec{q}(x, z)=\int_{a} \vec{u}^{3 D}(x, y, z) d y=-\frac{a^{3}}{12 \eta} \vec{\nabla}_{2} P \text { [Eq. 2 ], }
$$

and the bidimensional (2D) velocity $\vec{u}$ is defined from the average of the velocity $\vec{u}^{3 D}$ over the aperture with

$$
\vec{u}(x, z)=\frac{1}{a(x, z)} \int_{a} \vec{u}^{3 D}(x, y, z) d y=-\frac{a^{2}}{12 \eta} \vec{\nabla}_{2} P \text { [Eq. 3]. }
$$

Furthermore, considering the fluid to be incompressible, the Reynolds equation is obtained: $\vec{\nabla}_{2}\left(a^{3} \vec{\nabla}_{2} P\right)=0$. As boundary conditions of this equation, we impose the pressure at the inlet and outlet of the fracture (if $x=0, P=P_{0}$ and if $x=l_{x}, P=P_{l x}$, with $P_{0}>P_{l x}$ ) and consider impermeable sides at $z=0$ and $z=l_{z}$

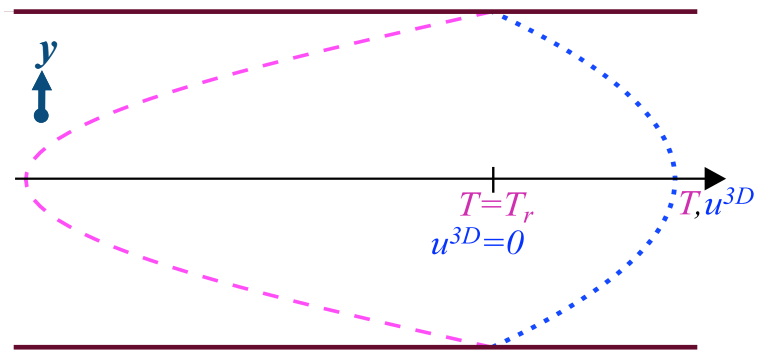

Figure 2: Local velocity quadratic profile (dotted line) and temperature quartic profile (dashed line) inside a fracture across the aperture at the mesh scale; arbitrary abscissa units. Along the fracture sides, $u^{3 D}=0$ and $T=T_{r}$, and the roots of the polynoms given by equations 1 and 5 are respected. Profil local parabolique de vitesse (ligne pointillée) et profil local quartique de température (ligne tiretée) dans la fracture, à travers l'ouverture. Le long des bords, $u^{3 D}=0$ et $T=T_{r}$, et les racines des polynômes donnés par les équations 1 et 5 sont respectées.

\section{Physics of thermal exchange}

On the basis of a classical description (e.g. [35]), we aim at modeling the fluid temperature when cold water is permanently injected at the inlet of a hot fracture at temperature $T_{0}$. As the conduction inside the rock is not taken into account (hypothesis of infinite thermal conduction inside the rock), the fracture sides are supposed to be permanently hot at the fixed temperature $T_{r}$. This hypothesis should hold for moderate time scales (e.g., months), after the fluid injection stabilized, and before the rock temperature significantly changed. The fluid temperature is controlled by the balance between thermal convection and conduction inside the fluid, which reads [14]: $\vec{u}^{3 D} \cdot \vec{\nabla} T=\chi \Delta T$ where $\chi$ is the thermal diffusivity of the fluid and $T$ the fluid temperature. We extend the local lubrication approximation by considering that the slopes of the fracture morphology are small enough to limit the conduction only along the $y$-axis. 
We suppose that the leading terms are the conduction along the $y$-axis and the in-plane convection (since there is no fluid velocity component along $\hat{y}$ ). Indeed, the off-plane free convection has been shown to be negligible (its magnitude is of the order of $\mathrm{km} / \mathrm{year}$ [2]). So the previous equation reduces to:

$$
\frac{\partial^{2} T}{\partial y^{2}}=\frac{\vec{u}_{x}^{3 D}}{\chi} \frac{\partial T}{\partial x}+\frac{\vec{u}_{z}^{3 D}}{\chi} \frac{\partial T}{\partial z}[\text { Eq. 4] }
$$

where $\vec{u}_{x}^{3 D}, \vec{u}_{z}^{3 D}$ are the in-plane components of the fluid velocity. The fluid is supposed to be at rock temperature along the fracture sides, and sufficiently far from the inlet. When we integrate Eq. 4 along the fracture aperture we assume that $\beta=q_{x} \frac{\partial T}{\partial x}+q_{z} \frac{\partial T}{\partial z}$ is independent of $y$, where $q_{x}$ and $q_{z}$ are the in-plane component of $\vec{q}$ defined in Eq. 2. Accordingly, we find that the temperature solution has a quartic profile (Figure 2) along the fracture aperture ${ }^{\ddagger}$ :

$$
T=-\frac{\beta}{2 a^{3} \chi}\left(y-y_{1}\right)\left(y-y_{2}\right)\left(y-\sqrt{5} y_{1}\right)\left(y-\sqrt{5} y_{2}\right)+T_{r} \text { [Eq.5], }
$$

where $y_{1}$ and $y_{2}$ are the local fracture sides coordinates.

Similarly to what is done for the hydraulic flow, we solve the thermal equation by integrating it along the fracture aperture (following the lubrication approximation extended to the thermal field). In particularly, when doing the balance of the energy fluxes, we express the advected free energy flux as $\rho c \int_{a} u^{3 D}(x, y, z)\left[T(x, y, z)-T_{0}\right] d y$. Accordingly we introduce:

$$
\bar{T}(x, z)=\frac{\int_{a} u^{3 D}(x, y, z) T(x, y, z) d y}{\int_{a} u^{3 D}(x, y, z) d y} \text { [Eq. 6] }
$$

which is an average of the temperature profile weighted by the local norm of velocity. We also use the Nusselt number $N u=-\varphi_{r} / \varphi_{\text {ref }}$ which compares the efficiency of the heat flow along the fracture boundaries:

$$
\varphi_{r}=-\left.\chi \rho c \frac{\partial T}{\partial y}\right|_{y=z_{1}, z_{2}} \text { to }
$$

the mesoscopic heat flow at the fracture aperture scale without convection: $\varphi_{\text {ref }}=\chi \rho c\left(T_{r}-\bar{T}\right) / a$. Using the polynomial expression of $T$ (in Eq. 5) and the definition of $\bar{T}$, we get $\beta=140 \chi\left(\bar{T}-T_{r}\right) /(17 a)$ and $N u=70 / 17$. Equation 4 leads then to:

$$
\vec{q} \cdot \vec{\nabla}_{2} \bar{T}+2 \frac{\chi}{a} N u\left(\bar{T}-T_{r}\right)=0 \text { [Eq. 7], }
$$

Boundary conditions are: $\bar{T}(0, z)=T_{0}$ at the inlet and $\bar{T}\left(l_{x}, z\right)=T_{r}$ at the outlet (with $l_{x}$ large enough). Any boundary condition for the temperature along $z=0$ or $z=l_{z}$ can be used as the hydraulic flow $\vec{q}$ is null there.

\footnotetext{
$\mp$ We compared our method to another algorithm based on a Lattice Boltzmann (LB) method, which does not reduce Navier-Stokes to a Stokes equation and does not hypothesize any lubrication approximation, in order to solve the velocity and temperature fields. From those results it appears that the analytical parabolic and quartic approximations (with the proper coefficients) of the respective fields are indeed consistent within a $5 \%$ error bar with the LB results.
}

We discretize this equation by using a first order finite difference scheme and finally get $\bar{T}$ by inverting the system using a biconjugated gradient method [23].

It is finally possible to get the three-dimensional temperature field $T$ anywhere within the fluid by using the previous $\beta$ expression and the quartic profile (Eq. 5). Figure 3 illustrates an example of temperature field for a given $z=z_{0}, T\left(x, y, z=z_{0}\right)$, obtained in that way from the bidimensional field $\bar{T}$ (shown in Figure 7) computed inside a variable aperture field (see Figure 4). Along any given cut at $x=x_{0}$, the temperature (represented by the color scale) follows a quartic law. The boundaries between the colors are isotherms and their shape does not follow any particular law.

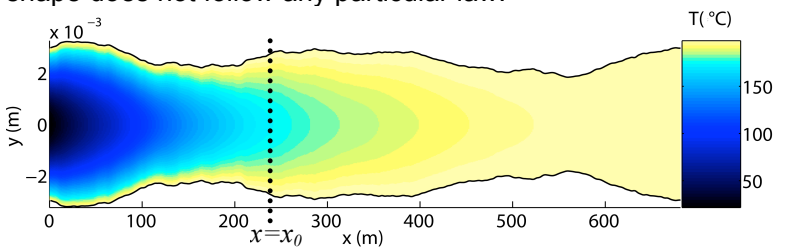

Figure 3: Example of temperature $T\left(x, y, z=z_{0}\right)$ inside a variable aperture between $\pm a\left(x, y, z=z_{0}\right) / 2$, computed from $\bar{T}$ shown in Figure 7 , in $z_{0}=700 m$. Exemple de température $T\left(x, y, z=z_{0}\right)$ à travers l'ouverture variable entre $\pm a\left(x, y, z=z_{0}\right) / 2$, calculé d'après $\bar{T}$ illustré Figure 7 , en $z_{0}=700 \mathrm{~m}$. L'échelle de couleur est linéaire.

Definition of characteristic quantities describing the computed hydraulic and thermal fields

Comparison to modeling without roughness

If we consider a fracture modeled by two parallel plates separated by a constant aperture $A$, then the gradient of pressure is constant all along the fracture as well as the hydraulic flow which is equal to:

$\vec{q}_{/ /}=-\frac{\Delta P}{l_{x}} \frac{A^{3}}{12 \eta} \hat{x}$, where the subscript // is for parallel plate conditions and $\Delta P=P_{l x}-P_{0}$. Under these conditions the analytical solution of Eq. 7 is:

$$
\bar{T}_{/ /}=\left(T_{0}-T_{r}\right) \exp \left(-\frac{x}{R_{/ /}}\right)+T_{r}{ }^{\text {[Eq. 8], }}
$$

where $R_{/ /}$is a thermal length describing the distance at which the fluid typically reaches the temperature of the surrounding rock. We have:

$$
R_{/ /}=\frac{A\left\|\vec{q}_{/ /}\right\|}{2 N u \chi}=-\frac{\Delta P}{l_{x}} \frac{A^{4}}{24 \eta N u \chi}=\frac{A P e}{N u} \text { [Eq. 9], }
$$

where $P e$ is the Péclet number defined by $P e=\left\|\vec{q}_{/ /}\right\| / 2 \chi$. $P e$ expresses the magnitude of the convection with respect to the conduction.

For rough fractures, we want to study whether the temperature profiles along $x$ at a coarse grained scale can still be described by Eq. 8 and if so, what is the impact of the fracture roughness on the thermal length $R$.

\section{Hydraulic aperture}

The hydraulic flow can be macroscopically described using the hydraulic aperture $H[6 ; 36]$, defined as the equivalent parallel plate aperture to get the macroscopic flow $\left\langle q_{x}\right\rangle$ under the pressure gradient $\Delta P / l_{x}$ :

$$
H=\left\langle-q_{x} \frac{12 \eta l_{x}}{\Delta P}\right\rangle^{1 / 3}[\text { Eq. 10] }
$$


where the quantity under bracket is the spatial average over $x$ and $y$. Note that the hydraulic aperture $H$ is an effective measure that can be estimated from hydraulic tests whereas the geometrical aperture $A$ is deduced from a direct measurement of the fracture geometry. If $H / A$ is higher than 1 , then the fracture is more permeable than parallel plates separated by $A$. Hydraulic apertures can also be defined locally as:

$$
h(x, z)=\left(-q_{x}(x, z) \frac{12 \eta l_{x}}{\Delta P}\right)^{1 / 3}[\text { Eq. 11]. }
$$

Local geometrical and hydraulic apertures are denoted here with small letters while the corresponding macroscopic variables (mean geometrical and hydraulic aperture) are in capital letters.

\section{Thermal aperture}

For the thermal aspect, once $\bar{T}$ is known, we aim at defining a thermal length $R$ like in Eq. 8. To do that, we define $\overline{\bar{T}}$, a $z$ average temperature which varies only along the forced gradient direction $x$, and weighted by the $2 \mathrm{D}$ fluid velocity $u_{x}$ to fulfill energy conservation:

$$
\overline{\bar{T}}(x)=\frac{\int_{l_{z}} u_{x}(x, z) \bar{T}(x, z) d z}{\int_{l_{z}} u_{x}(x, z) d z} \text { [Eq. 12]. }
$$

Then, based on the flat plate temperature solution (Eq. 8), we do a linear fit of $\ln \left[\left(\overline{\bar{T}}-T_{r}\right) /\left(T_{0}-T_{r}\right)\right\rfloor$ plotted as a function of $x$, and we use the slope of this fit to get the characteristic thermal length $R$. This fit is computed over the zone where the numerical precision of the fitted quantities is sufficient (larger than $\ln \left(2.10^{-6}\right)$ ). Similarly to the parallel plate case (Eq. 9), the thermal length $R$ can be used to define a thermal aperture $\Gamma$ :

$$
R=-\frac{\Delta P}{l_{x}} \frac{\Gamma^{4}}{24 \eta N u \chi},
$$

which means that a fracture modeled by parallel plates separated by a distance $\Gamma$ provides the same averaged thermal behavior as the rough fracture of mean geometrical aperture $A$.

\section{CASE STUDY AT SOULTZ-SOUS-FORETS (FRANCE)}

\section{Computation of apertures, hydraulic and thermal fields}

Let us consider the GPK3 and GPK2 wells of the deep geothermal drilling near Soultz-sous-Forêts (France), which are separated by a distance of about $600 \mathrm{~m}$ at roughly 5000 $\mathrm{m}$ of depth. From hydraulic tests [26], it has been shown that the hydraulic connection between both wells is relatively direct and straight. Sausse et al. (2008) [28] showed that actually a fault is linking GPK3 (at $4775 \mathrm{~m}$ ) to GPK2. This fault zone consists of a large number of clusters of small fractures which probably lead to complex hydraulic streamlines and heat exchanges. We study here a simplified model of this connecting fault zone between the wells using one single rectangular rough fracture. The size of the studied fracture is $l_{x} \times l_{v}=680 \times 1370 \mathrm{~m}^{2}$. Individual fracture apertures are typically of the order of $0.2 \mathrm{~mm}$ (Genter \& Jung, private communication) while the fracture zone is rather thicker (10 $\mathrm{cm}$ ) [28]. To account for this variability of the fault zone aperture, we use a probabilistic model of the geometrical aperture but with macroscopic properties that are consistent with in-situ observations: a mean aperture $A$ equal to 3.60 $\mathrm{mm}$ and its standard deviation to $\sigma=1.23 \mathrm{~mm}$. Figure 4 shows an example of a self-affine aperture randomly generated with the required parameters.

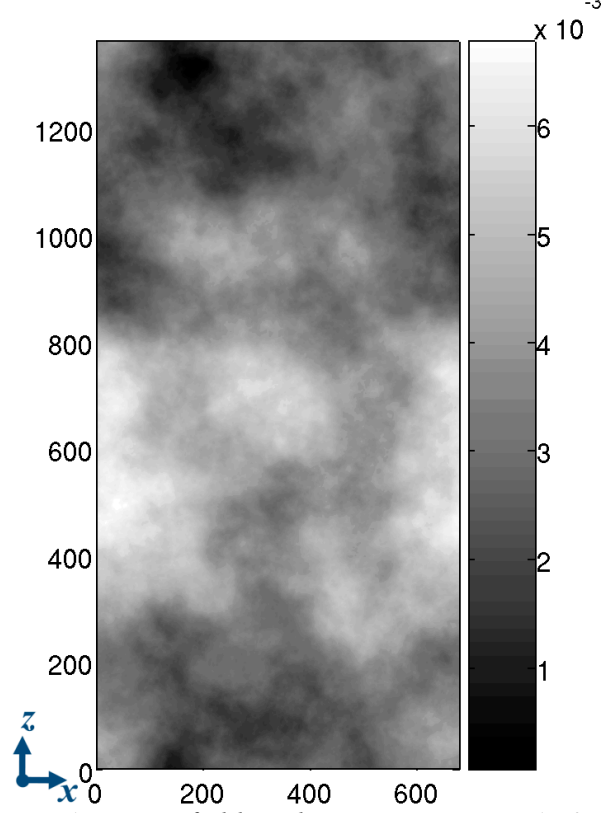

Figure 4 Aperture field with mean aperture $A=3.60 \mathrm{~mm}$ and variability of the aperture $\sigma=1.23 \mathrm{~mm}(\sigma / A=0.34)$. The color bar represents the aperture in $m$, the side units are plane spatial coordinates $(x, z)$, also in $m$.

Champ d'ouverture de moyenne $A=3.60 \mathrm{~mm}$ et de RMS $\sigma=1.23 \mathrm{~mm}(\sigma / A=0.34)$. La barre de couleur représente les valeurs d'ouverture en $m$ et les valeurs sur les bords sont les coordonnées spatiales $(x, z)$, aussi en $m$.

With little knowledge about the pressure conditions along the boundaries of this model, we assume that the two facing sides along $x$ of this rectangular fracture correspond to the inlet and outlet of the model where the pressure is homogeneous, respectively $P_{0}$ and $P_{l x}$. In other words, we assume the streamlines to be as straight as possible between both wells.

The pressure gradient is chosen as $\Delta P / l_{x}=-10^{-2} \mathrm{bar} / \mathrm{m}$, which corresponds to about 6 bars between the bottom of both wells. The dynamic viscosity is chosen to be $4 \times 10^{-4} \mathrm{~Pa}$.s (reference value for pure water at $10 \mathrm{~Pa}$ and $100^{\circ} \mathrm{C}$ from the table in Spurk \& Aksel, 2008 [32]). The Reynolds number rescaled with the fracture characteristic dimensions of the fracture [17] is equal to $R e^{\prime}=\left(\rho u_{x} a^{2}\right) /\left(\eta \cdot l_{x}\right)=0.026$ and the Péclet number is $P e=3.8 \times 10^{4}$.

Then we solve the hydraulic flow in the fracture domain and obtain the 2D velocity field, $\vec{u}$ defined in Eq. 3 . Figure 5 shows the spatial fluctuations of $\|\vec{u}\|$. For information, a parallel plate model separated by the chosen aperture $A$ would predict a homogeneous fluid velocity of $3.6 \mathrm{~m} / \mathrm{s}$ and a thermal length $R_{/ /}=33.3 \mathrm{~m}$. As we see in Figure 5 , the $2 \mathrm{D}$ velocity field exhibits interesting features: the fluid is rather immobile along the upper and lower borders of the fracture (close to $z=0$ and $z=l_{x}$ ) while most of the fluid flows very quickly through a channel in the middle of the fracture.

The macroscopic hydraulic aperture is deduced from the local hydraulic flow estimate (Eq. 10): $H=3.73 \mathrm{~mm}$, which is slightly higher than the mean mechanical aperture $A=3.60 \mathrm{~mm}$. Therefore, this fracture is more permeable than parallel plates separated by $A$. In other words the fracture is geometrically thinner than what one would expect from the knowledge of $H$ possibly inverted from an hydraulic test. However, the local hydraulic apertures $h$ (Eq. 11) range from nearly 0 to $5.43 \mathrm{~mm}$ (see in Figure 6). 


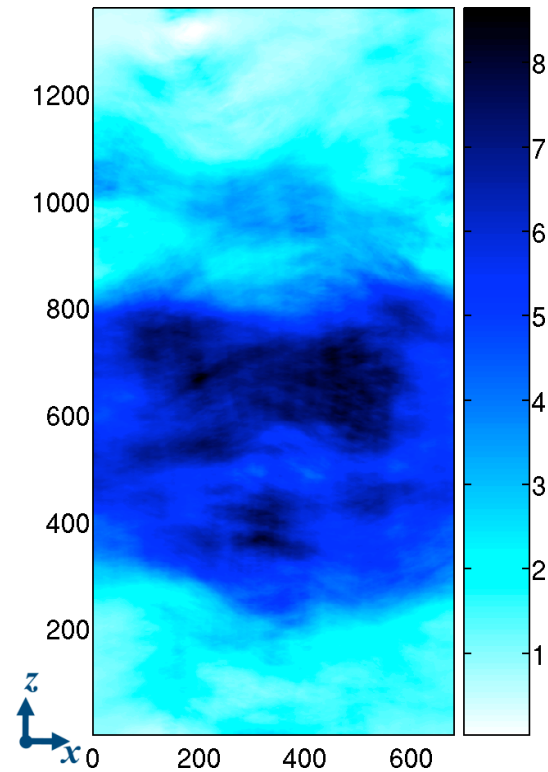

Figure 5: Color map of $u$, the $2 D$ velocity field norm in $\mathrm{m} / \mathrm{s}$. Dark areas correspond to very high velocity while light areas show static fluid. A linear pressure gradient is imposed between the left and right of the fracture. The spatial coordinates are in $m$.

Carte de $u$, la norme du champ de vitesse $2 D$ en $\mathrm{m} / \mathrm{s}$. Les zones sombres correspondent à une forte vitesse tandis que les zones claires indiquent un fluide immobile. Un gradient de pression linéaire est imposé entre les bords gauches et droits de la fracture. Les coordonnées spatiales sont en $m$.

From the average estimate of the fluid velocity, we can go back to our approximation of a linear inlet, even if the fracture is not vertical and does not intersect the well on a very long distance. We might estimate this distance from the following argument. The flowrate observed at Soultz is about $Q=20 \mathrm{~L} / \mathrm{s}$. Thus, using a velocity of about $u=3.6 \mathrm{~m} / \mathrm{s}$ and a fracture aperture equal to $3.6 \mathrm{~mm}$ implies that the well crosses such fractures over a cumulated length of about (neglecting the well radius):

$$
L=\frac{Q}{u A}=\frac{20 \times 10^{-3}}{3.6 \times 3.6 \times 10^{-3}} \approx 1.5 \mathrm{~m},
$$

which is effectively much smaller than the boundary size. However we expect the presence of connecting fractures between the well and the fault zone to be sufficiently permeable to define an effective linear inlet of constant effective pressure. All the results presented here are valid under any dimensioning which keeps the ratio $l_{x} / R_{/ /}$constant (here equal to 20.5): for instance the results apply for $l_{x}=690 \mathrm{~m}, A=10 \mathrm{~mm}$ and $\Delta P / l_{x}=-1.7 \times 10^{-4} \mathrm{bar} / \mathrm{m}$ (using the same fluid parameters).

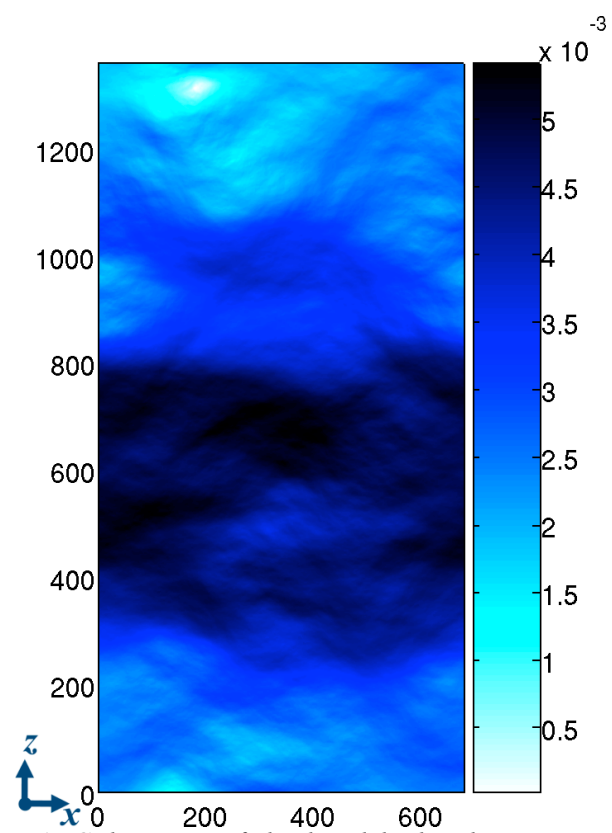

Figure 6: Color map of the local hydraulic aperture in $m$ computed from the variable aperture and velocity field shown in Figure 4 and Figure 5. The spatial coordinates are in $m$.

Carte de l'ouverture hydraulique locale en $m$, calculée d'après l'ouverture variable (Figure 4) et le champ de vitesses (Figure 5). Les coordonnées spatiales sont en $\mathrm{m}$.

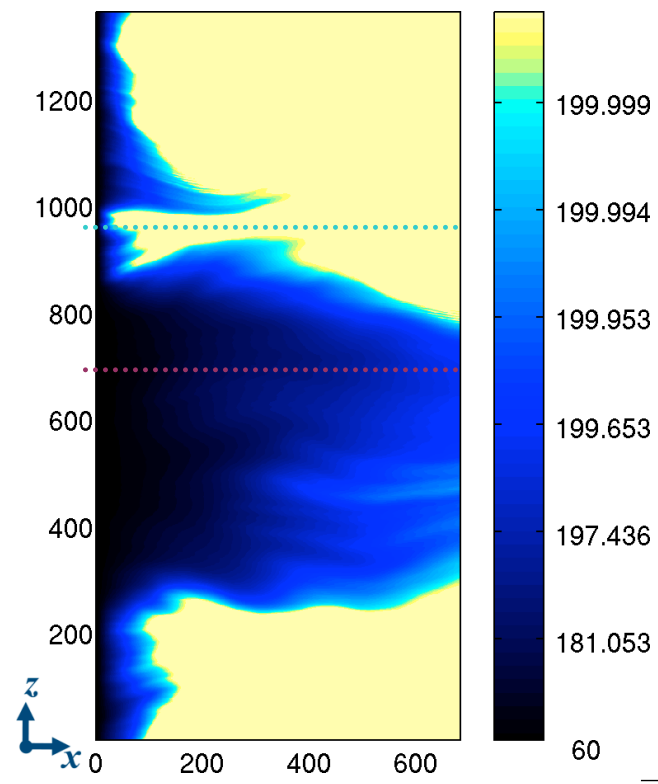

Figure 7: Map of the averaged temperature field $\bar{T}$ in Celsius degrees $\left({ }^{\circ} \mathrm{C}\right)$. The color bar changes exponentially; thus small variations slightly below the temperature rock $\left(200^{\circ} \mathrm{C}\right)$ are highly visible. The dotted lines indicate the location of the profiles of temperature $\bar{T}(x, z)$ shown in Figure 8 , for $z=960 \mathrm{~m}$ and $z=700 \mathrm{~m}$. The spatial coordinates are in $m$.

Carte du champ de température moyenné $\bar{T}$ en degrés Celcius $\left({ }^{\circ} \mathrm{C}\right)$. L'échelle de couleur change exponentiellement; les petites variations en dessous de la température de la roche $\left(200^{\circ} \mathrm{C}\right)$ sont donc très visibles. Les lignes en pointillées indiquent la position des profiles 
de températures $\bar{T}(x, z)$ montrés sur la Figure 8 , en $z=960 \mathrm{~m}$ et $z=700 \mathrm{~m}$. Les coordonnées spatiales sont en $\mathrm{m}$.

As we see, $\bar{T}$ is very inhomogeneous and also exhibits channeling. The chosen inlet temperature is $T_{0}=60^{\circ} \mathrm{C}$, the rock temperature is $T_{r}=200^{\circ} \mathrm{C}$ and the fluid diffusivity is $\chi=0.17 \mathrm{~mm}^{2} / \mathrm{s}$ (corresponding to water at $T=100^{\circ}$, from the table in Taine \& al., 2003 [34]). Note that the rock temperature will evolve over time in contrast to the one of our approximations. Indeed the rock thermal diffusivity is about $1 \mathrm{~mm}^{2} / \mathrm{s}$ which is larger than the fluid diffusivity $\left(\chi=0.17 \mathrm{~mm}^{2} / \mathrm{s}\right)$ but not sufficiently to be fully neglected.

However, $\bar{T}$ is rather different from a parallel plate solution. Indeed the solution is not invariant in $\hat{z}$. Different temperature profiles function of $x$ are shown in Figure 8. Two end-member types of behavior are plotted: temperature profiles at $z=960 \mathrm{~m}$ (curve iv) and $z=700 \mathrm{~m}$ (curve v). The temperature difference can be larger than $100^{\circ} \mathrm{C}$ in the inlet region. Even rather far from the inlet, for example at $x=200 \mathrm{~m}$, the temperature difference can still be of the order of $17^{\circ} \mathrm{C}$ $\left(200.0^{\circ} \mathrm{C}\right.$ for $z=960 \mathrm{~m}$, and $183.4^{\circ} \mathrm{C}$ for $\left.z=700 \mathrm{~m}\right)$. ). The temperature field $T(x, y, z=700 \mathrm{~m})$ is as well shown in Figure 3 , where we see how the temperature evolves along the $x$-axis and across the aperture. Temperature profiles can be compared to the one obtained for a parallel plate model where plates are separated by the aperture $A$ (curve iii) which reads from Eqs. 8 and 12: $\overline{\bar{T}}_{/ /}=\bar{T}_{/ /}$.

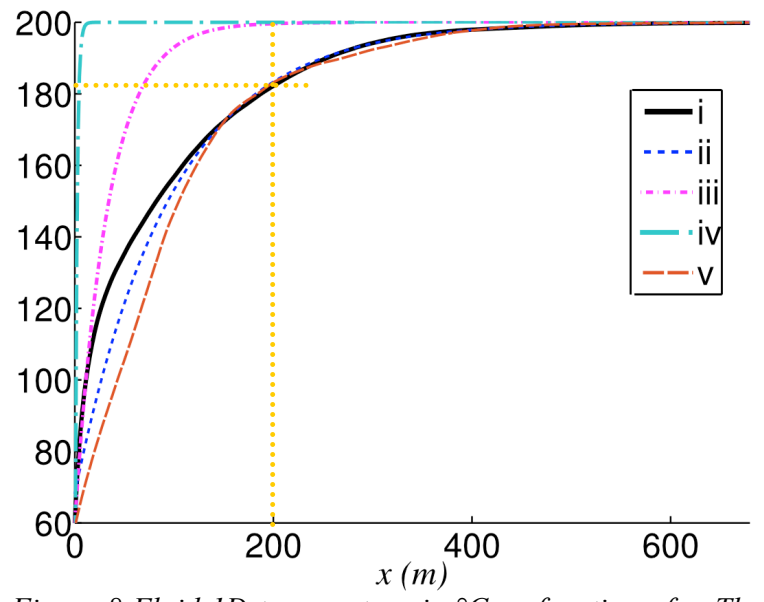

Figure 8 Fluid $1 D$ temperature in ${ }^{\circ} \mathrm{C}$ as function of $x$. The continuous black curve (i) shows the computed temperature $\overline{\bar{T}}$. The blue dashed curve (ii) is the fit of curve (i) with an exponential function. The dot dashed magenta curve (iii) is the fluid $1 D$ temperature by neglecting the self-affinity perturbation (inside flat parallel plates). The curves (iv) and (v) are the profiles of temperature $\bar{T}(x, z)$ for respectively $z=960 \mathrm{~m}$ and $z=700 \mathrm{~m}$ (see Figure 7). Température $1 D$ en degrés en fonction de $x$. La courbe continue noire (i) est le profil calculé $\overline{\bar{T}}$. La courbe bleue tiretée (ii) est le fit de la courbe (i) avec une fonction exponentielle. La courbe magenta (iii) est la température $1 D$ obtenue en négligeant la perturbation auto-affine (modèle de plaques parallèles). Les courbes (iv) et (v) sont les profiles de température $\bar{T}(x, z)$ respectivement en $z=960 \mathrm{~m}$ et $z=700 \mathrm{~m}$ (voir Figure 7)

Following this model (curve iii) the fluid should be at $199.7^{\circ} \mathrm{C}$ at $x=200 \mathrm{~m}$. If we compare $\overline{\bar{T}}_{/ /}$to the averaged observed temperature $\overline{\bar{T}}$ (defined in Eq. 12) (Figure 8, curve i), we see that $\overline{\bar{T}}_{/ /}$is not representative of the end-member types of behavior. Therefore, we model $\overline{\bar{T}}$ by using an adapted parallel law $\overline{\bar{T}}_{\text {mod }}$ (curve ii) which is an exponential law with a suitable thermal length $R$ :

$$
\overline{\bar{T}}_{\text {mod }}=\left(T_{0}-T_{r}\right) \exp \left(-\frac{x-x_{0}}{R}\right)+T_{r} \text { [Eq. 14], }
$$

where $R=97 \mathrm{~m}$ (i.e. $2.9 \times R_{/ /}$) and $x_{0}=-10 \mathrm{~m}$. Due to the choice of the minimization to obtain parameters $R$ and $x_{0}$ (least square applied on the semi-log plot), the beginning of the fit is not accurate. We see that the distance between wells $(600 \mathrm{~m}$ in our case study) is about 6 times larger than $R$. However owing to channeling the fluid temperature will not necessarily be in full equilibrium with the rock temperature at the out well. The thermal aperture is finally equal to $\Gamma=4.7 \mathrm{~mm}$, which is rather different from the geometrical aperture $A=3.6 \mathrm{~mm}$. A larger thermal aperture (compared to the geometrical one) means an inhibited thermalization on average.

\section{Temperature estimation with few parameters}

The knowledge of the spatial correlations rather than all the details of the geometrical aperture seems to be a key parameter to evaluate the hydraulic flow and the temperature of the fluid in a rough fracture. Indeed the macroscopic geometrical aperture $A$ brings too little information to characterize the heat exchange at the fracture scale. By contrast, it is impossible in particular for field measurements to know in detail the spatial variability of the local geometrical aperture $a$. Therefore we propose to characterize the macroscopic geometrical properties with more than a single value, using several parameters describing the largest spatial variations. Numerically, it is possible to obtain them by filtering the fracture aperture field in the Fourier domain.

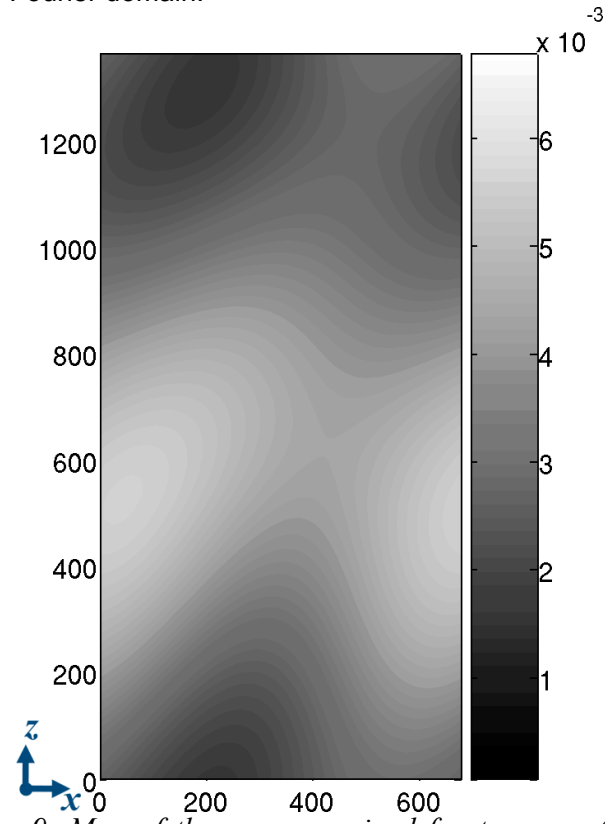

Figure 9: Map of the coarse-grained fracture aperture in $m$, obtained by filtering the aperture (Figure 4) keeping only the zero and $1^{\text {st }}$ Fourier modes along $x$ and $z$. The spatial coordinates are in $m$. Carte de l'ouverture géométrique à faible résolution spatiale, en $m$, obtenue en filtrant l'ouverture (Figure 4), en ne gardant que la moyenne et les $1^{\text {ers }}$ modes de Fourier sur $x$ et $z$. Les coordonnées spatiales sont en $m$. 
Figure 9 shows the aperture field displayed in Figure 4 once it has been filtered with the following criterion: only the Fourier coefficients fulfilling:

$\left(\frac{k_{x}}{2 \pi} l_{x}\right)^{2}+\left(\frac{k_{z}}{2 \pi} l_{z}\right)^{2} \leq 1$ are kept, where $k_{x}$ and $k_{z}$ are the wave vector coordinates along respectively the $x$ and $z$-axes. Since the Fourier transform is discrete, it means that we only keep the Fourier components corresponding to the wave number $(n x, n z)=(2 \pi / k x, 2 \pi / k z)$ in $\{(0,0) ;(0,1) ;(1,0)\}$ (i.e. the average $A$ and the first Fourier modes along $x$ and $z$ are left). Let us assume that we only have these data available to evaluate the hydraulic flow and heat exchange. Using the same method and the same parameters as previously, we compute the pressure field corresponding to the filtered aperture field. In Figure 10 we show the hydraulic aperture field we obtain. As we see, the high hydraulic aperture channel in the middle of the figure remains, while high frequency variations are removed. These large scale fluctuations of the hydraulic flow, computed from the knowledge of a very limited set of Fourier modes of the geometrical aperture, might be obtained from field measurements. Then the corresponding temperature field shown in Figure 11 is computed. The main features of the thermal field (Figure 7) are still visible: the main channel is at the same position and the values are of the same order of magnitude. Despite small local differences, this substitution model gives a relevant description of what thermally happens.

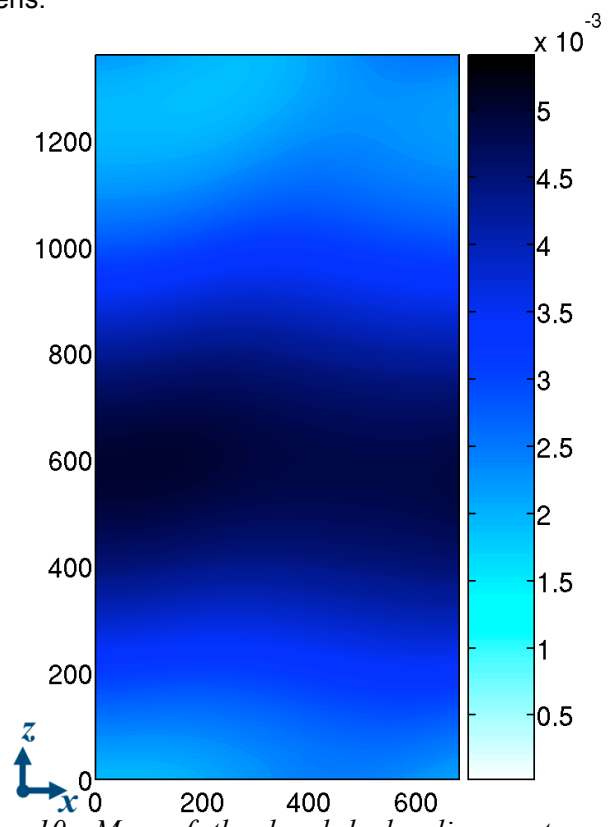

Figure 10: Map of the local hydraulic aperture in $\mathrm{m}$, obtained from the filtered geometrical aperture shown in Figure 9. This figure has to be compared to Figure 6 (same color bar). The spatial coordinates are in $m$. Carte de l'ouverture hydraulique en $m$ obtenue d'après les ouvertures géométriques filtrées de la Figure 9. Ce champ est comparable à celui de la Figure 6 (même échelle de couleur). Les coordonnées spatiales sont en $m$.

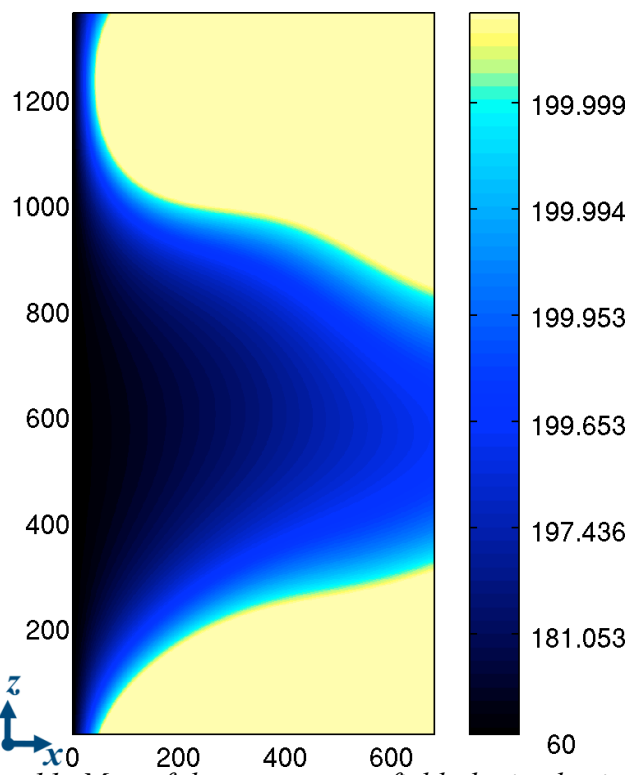

Figure 11: Map of the temperature field obtained using the previous coarse-grained aperture and its corresponding hydraulic results (Figure 9 and Figure 10). The color scale is in ${ }^{\circ} \mathrm{C}$ and it changes exponentially. The spatial coordinates are in $\mathrm{m}$. Carte de température obtenue en utilisant les ouvertures filtrées et les résultats hydrauliques correspondant (Figure 9 and Figure 10). Les coordonnées spatiales sont en $m$.

\section{CONCLUSIONS}

We propose a numerical model to estimate the impact of the fracture roughness on the heat exchange at the fracture scale between a cold fluid and the hot surrounding rock. We assume the flow regime to be permanent and laminar. The numerical model is based on a lubrication approximation for the fluid flow (Reynolds equation). We also introduce a "thermal lubrication" approximation which leads to a quartic profile of the temperature across the aperture. It is obtained by assuming that the in-plane convection is dominant with respect to the in-plane conduction (i.e. high in-plane Péclet number). The lubrication approximation implies also that the off-plane convection is neglected; subsequently the heat conduction initiated by the temperature difference between the rock and the fluid is supposed to be the major off-plane phenomenon.

Our model shows that the roughness of the fracture can be responsible for fluid channeling inside the fracture. In this zone of high convection, the heat exchange is inhibited, i.e. the fluid needs a longer transport distance to reach the rock temperature. Spatial variability of the temperature is characterized on average by a thermal length and a thermal aperture.

In this article, we illustrate our modeling with a case study at the geothermal reservoir of Soultz-sous-Forêts, France, with a rough aperture which leads to inhibited thermal exchanges owing to a strong channeling effect. With other compatible aperture fields (not illustrated here) we observe that the roughness may also highly reduce the convection because of hydraulic barriers perpendicular to the main flow. With these later configurations, the heat exchange is locally enhanced with a high conduction compared to convection. In any case, we notice that the temperature distribution is strongly affected by the space variability of the hydraulic flow.

From the numerical solutions, we see that the mean geometrical aperture provides too little information to characterize the variability of the fluid flow and fluid temperature. In contrast, the knowledge of the dominant 
spatial variation of the geometrical aperture field (here obtained by keeping only the largest scale fluctuations using Fourier filtering) provides interesting information about the spatial pattern of the hydraulic and thermal fields. The macroscopic spatial correlation of the aperture is shown to be an important parameter ruling the hydro-thermal behavior. Note that we considered a self-affine model for the aperture roughness, but other types of geometrical descriptions of this roughness (given either by constraints from field measurements, or other kind of geometrical models), could be evenly considered using the type of simulations described here.

We thank Albert Genter, Reinhard Jung Marion, Patrick Nami, Marion Schindler, Eirik G. Flekkøy, Stéphane Roux, Jose S. Andrade Jr. and Yves Méheust for fruitful discussions. This work has been supported by the EHDRA project, the REALISE program and the French Norwegian PICS project.

\section{REFERENCES}

[1] D. Bachler, T. Kohl, L. Rybach, Impact of graben parallel faults on hydrothermal convection - rhine graben case study, Phys. Chem. Earth 28 (2003) 431-441.

[2] A. Bataillé, P. Genthon, M. Rabinowicz, B. Fritz, Modeling the coupling between free and forced convection in a vertical permeable slot: Implications for the heat production of an Enhanced Geothermal System, Geothermics 35 (2006) 654-682.

[3] G.K. Batchelor, An introduction to fluid dynamics, Cambridge University Press, Cambridge, UK, 2002, 615 p.

[4] J.M. Boffa, C. Allain, J.P. Hulin, Experimental analysis of fracture rugosity in granular and compact rocks, Eur. Phys. J. Appl. Phys. 2 (1998) 281-289.

[5] E. Bouchaud, Scaling properties of cracks. J. Phys. Cond. Matter 9 (1997) 4319-4344.

[6] S.R. Brown, Fluid flow through rock joints: the effect of surface roughness. J. Geophys. Res., 92 (1987) 1337-1347.

[7] S.R. Brown, C.H. Scholz, Broad bandwidth study of the topography of natural rock surfaces. J. Geophys. Res. 90 (1985) 12575-12582.

[8] B.L. Cox, J.S.Y. Wang, Fractal surfaces: measurement and application in earth sciences, Fractal 1 (1993) 87-115.

[9] S. Gentier, X. Rachez, C. Dezayes, A. Hosni, A. Blaisonneau, A. Genter, D. Bruel, Thermohydro-mechanical modelling of the deep geothermal wells at Soultz-sousForêts, Proceedings of EHDRA scientific conference (2005).

[10] A. Gérard, A. Genter, T. Kohl, P. Lutz, P. Rose, F. Rummel, The deep EGS (Enhanced geothermal System) project at Soultz-sous-Forêts (Alsace, France), Geothermics 35 (2006) 473-483.

[11] N. Heuer, T. Küpper, D. Windelberg, Mathematical model of a Hot Dry Rock system, Geophys. J. Int. 105 (1991) 659-664.

[12] K. Iwai, Fundamental Studies of Fluid Flow through a single fracture, Ph.D. Thesis, University of California, Berkeley (1976).

[13] O. Kolditz, C. Clauser., Numerical simulation of flow and heat transfer in fractured cristalline rocks: application to the hot dry rock site in Rosemanowes (U.K.), Geothermics 27 (1998) 1-23.
[14] L. Landau, E. Lifchitz, Physique théorique mécanique des fluides, (3rd Ed.), Ed. MIR-Ellipses, Paris, France, 1994, pp. 280.

[15] Y. Méheust, Y. Ph.D. thesis, Ecoulements dans les fractures ouvertes, Université Paris Sud (2002).

[16] Y. Méheust, J. Schmittbuhl, Flow enhancement of a rough fracture, Geophys. Res. Lett. 27 (2000) 2989-2992.

[17] Y. Méheust, J. Schmittbuhl, Geometrical heterogeneities and permeability anisotropy of rough fractures, J. Geophys. Res. 106 (2001) 2089-2102.

[18] Y. Méheust, J. Schmittbuhl, Scale effects related to flow in rough fractures, PAGEOPH 160 (2003) 1023-1050.

[19] S. Neuman, Trends, prospects and challenges in quantifying flow and transport through fractured rocks, Hydrogeol. J. 13 (2005) 124-147.

[20] O. Pinkus, B. Sternlicht, Theory of hydrodynamic Lubrication, Mc Graw-Hill, New York, 1961, 465p.

[21] F. Plouraboué, P. Kurowski, J.M. Boffa, J.P. Hulin, S. Roux, Experimental study of the transport properties of rough self-affine fractures, J. of Contaminant Hydrology 46 (2000) 295-318.

[22] W.L. Power, T.E. Tullis, S.R. Brown, G.N. Boitnott, C.H. Scholz, Rhougness of natural fault surfaces, Geophys. Res. Lett. 14 (1987) 29-32.

[23] W.H. Press, S.A. Teukolsky, W.T. Vetterling, B.P. Flannery, Numerical Recipes, Cambridge University Press, New York, USA, 1992, 994p.

[24] X. Rachez, S. Gentier, A. Blaisonneau, Current status of BRGM modeling activities at the Soultz EGS reservoir: hydro-mechanical modeling of the hydraulic stimulation tests and flow and transport modelling of the in-situ tracer test. Proceedings of EHDRA scientific conference (2007).

[25] S. Roux, J. Schmittbuhl, J.P. Vilotte, A. Hansen, Some physical properties of self-affine rough surfaces, Europhys. Lett. 23 (1993) 277-282.

[26] B. Sanjuan, J.L. Pinault, P. Rose, A. Gerard, M. Brach, G. Braibant, C. Crouzet, J.C. Foucher, A. Gautier, S. Touzelet (2006), Tracer testing of the geothermal heat exchanger at Soultz-sous-Forets (France) between 2000 and 2005, Geothermics 35 (2006) 622-653.

[27] S. Santucci, K.J. Maløy, A. Delaplace, J. Mathiesen, A. Hansen, J.Ø. Haavig Bakke, J. Schmittbuhl, L. Vanel, P. Ray, Statistics of fracture surfaces, Physical Review E 75 (2007) 016104 6p.

[28] J. Sausse, C. Dezayes, A. Genter, A. Bisset, Characterization of fracture connectivity and fluid flow pathways derived from geological interpretation and 3D modelling of the deep seated EGS reservoir of Soultz (France). Proceedings, thirty-Third workshop on Geothermal Reservoir Engineering, Stanford, California (2008).

[29] J. Schmittbuhl, S. Gentier, S. Roux, Field measurements of the roughness of fault surfaces, Geophys. Res. Lett. 20 (1993) 639-641.

[30] J. Schmittbuhl, F. Schmitt, C. Scholz, Scaling invariance of crack surfaces, J. Geophys. Res. 100 (1995) 5953-5973. 
[31] J. Schmittbuhl, A. Steyer, L. Jouniaux, R. Toussaint, Fracture morphology and viscous transport, Int. J. Rock Mech. Min. Sci. 45 (2008) 422-430.

[32] J.H. Spurk, N. Aksel, Fluid Mechanics, (2nd Ed.), Springer, Berlin, Germany, 2008, pp.516.

[33] G.G. Stokes, On the theories of the internal friction of fluids in motion, and of the equilibrium and motion of elastic solids. Trans. Cambr. Phil. Soc, 8 (1846) 287-319.

[34] J. Taine, J.P. Petit, Transferts thermiques, (3rd Ed.), Dunod, Paris, France, 2003 , pp.449.

[35] D.L. Turcotte, G. Schubert, Geodynamics, (2nd Ed.), Cambridge University Press, Cambridge, UK, 2002, pp.262264.

[36] R.W. Zimmerman, S. Kumar, G.S. Bodvarsson, Lubrication Theory Analysis of Rough-Walled Fractures, Int. J. Rock. Mech. 28 (1991) 325-331. 